EL MUHASABA: Jurnal Akuntansi (e-Journal)

Volume 13 , No. 1, Tahun 2022

P ISSN: 2086-1249 ; E ISSN: 2442-8922

\title{
LAPORAN KEUANGAN BADAN AMIL ZAKAT NASIONAL (BAZNAS): PERSPEKTIF AKUNTANSI SYARIAH DAN PENCEGAHAN FRAUD
}

\author{
Riskiyatur Rohemah', Mohammad Nizarul Alim² \\ Universitas Trunojoyo Madura 1,2, Jl. Raya Telang PO.Box. 2 Kamal, Bangkalan-Madura, \\ 69162, Indonesia \\ e-mail: riskiyaturrohemah@gmail.com ${ }^{1}$
}

\begin{abstract}
The Indonesian Institute of Accountants (IAI) as an accounting professional organization in Indonesia striven to contribute in the context of realizing a good accounting system for an OPZ, through the published of PSAK 109. This study aims to analyze and qualitatively the application of PSAK No. 109 on BAZNAS. This study used descriptive qualitative method. The data used in this research is secondary data. Secondary data is obtained from the financial statements of BAZNAS. Based on the data that has been obtained and the results of the analysis conducted by researchers through the analysis of the application of PSAK No. 109 in the financial statements of BAZNAS, that the financial statements of BAZNAS are due with PSAK No. 109 in terms of recording and completeness of its financial statements, although it does not include non-halal fund transactions. However, it is still necessary to improve the computerized system on financial reporting and monitoring system to prevent fraud in the financial statements presented so as to achieve public trust and transparency in publishing information about the financial statements.
\end{abstract}

Keywords: BAZNAS; financial reports; PSAK 109; fraud

\begin{abstract}
Abstrak
Ikatan Akuntan Indonesia (IAI) sebagai organisasi profesi akuntan di Indonesia berupaya memberikan kontribusi dalam rangka mewujudkan sistem akuntansi yang baik dari suatu OPZ, melalui diterbitkannya PSAK 109. Penelitian ini bertujuan untuk menganalisis dan mengetahui secara kualitatif tentang penerapan PSAK No. 109 pada BAZNAS. Penelitian ini menggunakan metode deskriptif kualitatif. Data yang digunakan dalam penelitian ini adalah data sekunder. Data sekunder diperoleh dari laporan keuangan BAZNAS. Berdasarkan pada data yang telah diperoleh dan hasil analisis yang dilakukan oleh peneliti melalui analisis penerapan PSAK No. 109 dalam laporan keuangan BAZNAS, bahwa laporan keuangan BAZNAS telah sesuai dengan PSAK No. 109 dari sisi pencatatan dan kelengkapan laporan keuangannya, meskipun belum mencantumkan transaksi dana non halal. Namun demikian, masih perlu adanya perbaikan sistem komputerisasi dalam laporan keuangan dan sistem pemantauan untuk mencegah terjadinya kecurangan dalam laporan keuangan yang disajikan sehingga mencapai kepercayaan publik dan transparansi dalam mempublikasikan informasi tentang laporan keuangannya.
\end{abstract}

Kata kunci: BAZNAS; laporan keuangan; PSAK 109; fraud

\section{PENDAHULUAN}

Ekonomi syariah sebagai sistem merupakan induk dari segala aktivitas perekonomian yang dilakukan dengan berpedoman kepada syariat Islam. Sistem ekonomi syariah dalam praktiknya memiliki asas, nilai serta tujuan yang wajib dimiliki dan dipahami para aktivis ekonomi untuk menguatkan ekonomi syariah, baik operasional maupun produknya (Muhammad, 2021). Terdapat 3 pilar untuk menguatkan ekonomi syariah yaitu industri halal, lembaga keuangan syariah dan 
Riskiyatur Rohemah ${ }^{1}$ dan Mohammad Nizarul Alim²: Laporan Keuangan Badan Amil Zakat Nasional (BAZNAS): Perspektif Akuntansi Syariah dan Pencegahan Fraud

filantropy syariah (KNKS, 2019). Industri Halal merupakan pilar utama dalam pengembangan ekonomi syariah. Contohnya adalah industri makanan dan hasil pertanian halal, fashion busana muslim, Obat-obatan dan produk kecantikan, dan industri pariwisata. Perkembangan industri halal tersebut mempunyai peran penting untuk mendukung pelaksanaan pembangunan nasional. Oleh karena itu, sistem keuangan syariah dapat berintegrasi dengan baik seiring dengan perkembangan ekonomi syariah. Seiring dengan perkembangannya lembaga keuangan syariah sebagai pilar kedua mendapatkan atensi yang cukup besar dan signifikan. Perkembangan keuangan syariah saat ini sudah mengarah kepada maksimalisasi potensi zakat, infaq, sedekah dan wakaf, meskipun pada kenyataannya masih didominasi oleh perbankan. Sementara dalam pilar ketiga, efektifitas lembaga filantropy syariah menjadi pendukung dalam pengembangan ekonomi syariah.

Pada tahun 2020, Komite Nasional Ekonomi dan Keuangan Syariah (KNEKS) mendapatkan penghargaan sebagai global-hub ekonomi syariah dan industri halal dunia dalam acara GIFA Islamic Finance Advocacy Award 2020. Kemudian tahun 2021, KNEKS kembali menerima penghargaan sebagai Global Islamic Finance Leadership Award 2021 untuk kategori institusi. Hal ini menunjukkan antusiasme masyarakat terhadap tumbuhnya praktik ekonomi syariah sangat tinggi (Disemadi dan Prananingtyas, 2019). Salah satu yang menjadikan Indonesia sebagai negara paling dermawan di dunia berdasarkan hasil survey Charities Aid Foundation (CAF) dalam World Giving Index 2021 adalah kontribusi lembaga yang mengelola filantropy syariah seperti lembaga amil zakat. Zakat yang dipraktikkan secara luas di Indonesia merupakan bentuk amal tradisional Islam yang hasilnya dibagikan kembali kepada orang yang membutuhkan. Laporan dari hasil survey CAF 2021 menunjukkan hasil bahwa pembayaran Zakat sangat tinggi pada tahun 2020 yakni sebesar $83 \%$. Hal ini dikarenakan pada tahun tersebut merupakan awal pandemi. Oleh karena itu, untuk menegakkan aturan agama tentang zakat, mendirikan lembaga zakat sangat penting untuk mengelola pengumpulan zakat dan mendistribusikan dana yang terkumpul (Pamuncak et al., 2021).

Penelitian Samman et al, (2009), Furqoni et al, (2018) dan Azizah (2018) menyebutkan zakat lebih memiliki tujuan untuk mengentaskan kemiskinan dan tekanan sosial, tidak hanya terbatas untuk menyantuni delapan asnaf. Sedangkan, Miah (2021) menyebutkan bahwa melalui program berbasis Zakat di Bangladesh, dapat meningkatkan kesadaran sosial masyarakat miskin. Program tersebut seperti pengembangan keterampilan dan pendidikan, menciptakan akses ke layanan kesehatan, sanitasi kebersihan, dan mempromosikan nilai-nilai agama. Penyaluran zakat dapat dilakukan di berbagai bidang, baik bidang kesehatan maupun pendidikan. Selain itu, lembaga zakat dapat memberikan bantuan untuk mendukung usaha kecil karena hal ini termasuk dalam penyaluran zakat produktif. Sehingga pada prinsipnya, zakat disalurkan dalam dua pendekatan yaitu konsumtif dan produktif (Hartono et al., 2021). Penerimaan dana zakat dianggap rendah disebabkan oleh pertama masalah kesadaran, kesadaran yang dimaksud adalah dalam menyalurkan zakatnya melalui Organisasi Pengelola Zakat (OPZ). Kedua, karena kurangnya informasi dan sosialisasi yang diperoleh dari organisasi tersebut. Fenomena tersebut dapat membuat ketimpangan sosial dan ekonomi (Wahab, et al, 
Riskiyatur Rohemah ${ }^{1}$ dan Mohammad Nizarul Alim²: Laporan Keuangan Badan Amil Zakat Nasional (BAZNAS): Perspektif Akuntansi Syariah dan Pencegahan Fraud

2017). Sehingga OPZ harus berhati-hati dalam menyalurkan zakat yang sudah dipercayakan kepadanya, agar masyarakat dapat meyakini bahwa dengan adanya OPZ tidak akan ada penyelewengan dana zakat. Maka dari itu, perlu langkah dan prosedur yang tepat dalam menilai pendistribusian zakat oleh BAZNAS.

Masalah yang terjadi pada dasarnya adalah kredibilitas OPZ, oleh karena itu untuk meningkatkan kepercayaan dan kredibilitas OPZ, harus dibuat beberapa kriteria pemilihan pengelola zakat agar efektivitas pengelolaan zakat tidak terhambat. Sehingga, setiap lembaga pengelola zakat diwajibkan mempunyai pemahaman dan pengetahuan tentang aturan zakat menurut prinsip-prinsip syariah, serta adanya dukungan pengendalian internal yang memadai dan Good Corporate Governance (BAZNAS, 2016). Dalam mewujudkan system akuntansi yang baik dalam Organisasi Pengelola Zakat, Ikatan Akuntan Indonesia (IAI) berupaya memberikan kontribusi dengan diterbitkannya PSAK 109 tentang Akuntansi Zakat dan Infak/Sedekah. Pedoman standardisasi ini melakukan penyusunan dan pencatatan transaksi laporan keuangan yang dibuat oleh OPZ (Rahman, 2015). Sehingga, artikel ini bermaksud untuk menganalisis laporan keuangan Badan Amil Zakat Nasional (BAZNAS) berdasarkan perspektif akuntansi syariah dan nilai-nilai syariah serta pencegahan fraud.

\section{METODE}

Penelitian ini bertujuan untuk menganalisis laporan keuangan yang disajikan oleh BAZNAS berdasarkan perspektif akuntansi syariah dan pencegahan fraud. Penelitian ini menggunakan penelitian kualitatif deskriptif dengan mendeskripsikan dan menganalisis laporan keuangan BAZNAS. Data penelitian adalah data sekunder laporan keuangan BAZNAS yang meliputi penyajian dan pengungkapan laporan keuangan dalam bentuk Catatan Atas Laporan Keuangan. Metode analisis penelitian menggunakan analisis konten terhadap laporan keuangan BAZNAS dan analisis perbandingan (komparasi) laporan keuangan BAZNAS dengan perspektif akuntansi syariah berdasarkan PSAK 109 tentang Akuntansi Zakat dan Infak/Sedekah terkait dengan penyajian laporan keuangan dan pengungkapan laporan keuangan dapat digunakan sebagai analisis pencegahan fraud. Analisis penyajian laporan untuk mengetahui kelengkapan unsur dan akun laporan keuangan sedangkan analisis pengungkapan dalam catatan atas laporan keuangan untuk mengetahui keterkaitannya dengan pencegahan fraud.

\section{HASIL DAN PEMBAHASAN}

OPZ merupakan organisasi nirlaba yang pendiriannya berdasarkan prinsip syariah. OPZ umumnya memiliki karakteristik yang sama dengan organisasi nirlaba lainnya yaitu memiliki sumber daya seperti dana, barang dan lain-lain dari para donatur. Selan itu, OPZ juga menghasilkan berbagai jasa dalam bentuk komunitas layanan meskipun tujuannya bukan untuk menghasilkan keuntungan. 
Riskiyatur Rohemah ${ }^{1}$ dan Mohammad Nizarul Alim²: Laporan Keuangan Badan Amil Zakat Nasional (BAZNAS): Perspektif Akuntansi Syariah dan Pencegahan Fraud

Namun, karena keberadaannya berdasarkan prinsip syariah, maka OPZ secara khusus berbeda dengan lembaga non profit secara umum. Perbedaan tersebut terkait dengan ketentuan muzakki, ketentuan dan jenis barang yang harus dibayar, besaran dan nilai zakat yang harus dikeluarkan, dan yang berhak menerima zakat (Nugraha, et al, 2018). Untuk mengetahui segala kegiatan yang dilakukan oleh lembaga zakat, laporan keuangan merupakan hal yang sangat penting oleh karena itu harus dicatat dengan baik dan benar supaya dapat dipercaya oleh publik.

Menurut Juwaini yang dikutip dalam Afflah (2011) mengatakan bahwa kualitas pengelolaan lembaga zakat harus diukur dengan tiga kata kunci, yaitu:

1. Amanah, salah satu syarat mutlak yang harus dimiliki oleh setiap lembaga amil zakat.

2. Profesional, diartikan sebagai sesuatu yang menuntut keterampilan khusus dalam menjalankan sesuatu dengan efektif dan efisien untuk mencapai tujuan yang maksimal.

3. Transparan, semakin transparan dalam mengelola zakat, akan tercipta sistem pengendalian yang baik karena dalam mengelola zakat tidak hanya melibatkan dalam organisasi tetapi juga melibatkan pihak luar. Transparansi dalam zakat manajemen yang diwujudkan dalam penyajian laporan keuangan yang diterbitkan oleh OPZ sehingga akan menghilangkan kecurigaan dan ketidakpercayaan masyarakat, khususnya para donatur.

Indrijatiningrum (2004) berpendapat untuk mengembangkan pengelolaan zakat serta untuk meningkatkan realisasi pengumpulan zakat yang perlu dilakukan adalah meningkatkan transparansi dan akuntabilitas, serta meningkatkan profesionalisme dan kredibilitas. Sebagai organisasi pengelola dana, aspek transparansi dan akuntabilitas adalah modal utama bagi OPZ untuk mendapatkan kepercayaan dari publik. Peningkatan tersebut harus dijunjung tinggi, karena masih menjadi kelemahan OPZ (Nugraha, et al, 2018).

Kustiawan (2012: 19) menjelaskan bahwa kebermanfaatan laporan keuangan dilihat dari informasi yang disajikan dalam laporan keuangan yang dapat dipahami, relevan, andal, serta dapat dibandingkan. Pada umumnya laporan keuangan hanya menggambarkan efek dari peristiwa masa lalu, sehingga tidak diharuskan untuk menyediakan informasi non-keuangan. Jadi, Laporan keuangan tidak memberikan semua informasi yang mungkin dibutuhkan oleh pihak-pihak yang berkepentingan dengan Amil Zakat.

Adapun komponen laporan keuangan Amil Zakat PSAK 109 adalah sebagai berikut:
a. Laporan posisi keuangan
b. Laporan perubahan dana
c. Laporan perubahan aset kelolaan
d. Laporan arus kas
e. Catatan atas laporan keuangan 
Riskiyatur Rohemah ${ }^{1}$ dan Mohammad Nizarul Alim²: Laporan Keuangan Badan Amil Zakat Nasional (BAZNAS): Perspektif Akuntansi Syariah dan Pencegahan Fraud

Laporan keuangan berisi kondisi kesehatan dan kinerja keuangan yang berfungsi sebagai alat informasi yang menghubungkan entitas dengan pihak yang berkepentingan (Saidah, 2020). Penyajian laporan keuangan BAZNAS mengacu kepada SAK Syariah yang diterbitkan oleh IAI yaitu PSAK 109 yang ruang lingkupnya terbatas pada amil zakat yang menerima dan menyalurkan zakat, infaq, dan shodaqoh. Akuntansi syariah berkaitan dengan pengakuan dan pencatatan transaksi dan pengungkapan hak dan kewajiban secara adil (Widiana, 2018).

Berdasarkan dari hasil analisis, laporan keuangan BAZNAS memuat 5 komponen yang sesuai PSAK 109, yaitu laporan posisi keuangan, laporan perubahan dana, laporan aset kelolaan dan laporan arus kas serta catatan atas laporan keuangan. Namun, dalam komponen catatan atas laporan keuangan BAZNAS tidak disajikan secara langsung karena catatan atas laporan keuangan sudah merupakan bagian yang tidak terpisahkan dari laporan keuangan secara keseluruhan. Artinya, secara tidak langsung laporan catatan atas laporan keuangan sudah termasuk ke dalam 4 komponen laporan keuangan lainnya, yaitu laporan posisi keuangan, laporan perubahan dana, laporan aset kelolaan dan laporan arus kas serta merupakan referensi silang atau contoh dalam dokumen yang mengacu pada 4 komponen laporan keuangan amil lainnya. Selain itu, catatan atas laporan keuangan yang tidak dipublikasikan maka dapat diartikan pengungkapan terhadap laporan keuangan kurang transparan karena pihak pengguna kurang dapat mengetahui kebijakan akuntansi terkait dengan penerimaan serta penyaluran dan pendayagunaan maupun penerima manfaat. Sehingga, implikasinya untuk pencegahan fraud kurang andal dari pihak pengguna dan stakeholder.

Mubarok dan Yadiati (2017) mengemukakan bahwa kualitas laporan keuangan merupakan salah satu tujuan internal kegiatan pengendalian. Prosedur pengendalian membantu organisasi untuk merealisasikan ransaksi keuangan yang dapat diakui, dicatat, valid, lengkap, dan disajikan tepat waktu. Prosedur pengendalian juga dapat mengurangi risiko penipuan dan menghilangkan keraguan tentang keuangan data, catatan dan laporan keuangan secara umum (Nurhayati, et al, 2020).

Hasil analisis menunjukkan bahwa laporan perubahan dana tidak ada akun dana non halal. Dana nonhalal merupakan kumpulan dana dari kegiatan yang tidak sejalan dan sesuai dengan prinsip-prinsip syariah, misalnya bunga yang bersumber dari bank konvensional. Hasil ini selaras dengan Hisamuddin (2014), yang meneliti BAZNAS Lumajang juga tidak mengungkapkan dana non halal dalam laporan keuangannya. Tidak adanya akun dana non halal mengindikasikan bahwa BAZNAS tidak menggunakan rekening bank konvensional sehingga tidak ada penerimaan bunga bank. Dana non halal dalam OPZ umumnya bersumber dari bunga bank karena OPZ menggunakan tabungan konvensional. 
Riskiyatur Rohemah ${ }^{1}$ dan Mohammad Nizarul Alim²: Laporan Keuangan Badan Amil Zakat Nasional (BAZNAS): Perspektif Akuntansi Syariah dan Pencegahan Fraud

Dana nonhalal biasanya didapatkan atau terjadi pada kondisi yang tidak diinginkan oleh entitas syariah karena secara prinsip dilarang dan terpisah dari dana zakat, infak dan sedekah. Dana nonhalal biasanya disalurkan sesuai dengan kaidah syariah dan Pengelolaan dana non halal tidak bisa dikelola secara sembarangan karena dalam PSAK sudah diatur mengenai prosedur pengelolaan dana non halal serta telah diungkapkan oleh OPZ dalam keadaan yang tidak diinginkan, sehingga tidak selalu muncul dalam laoran keuangan BAZNAS yang bersifat akuntabel.

Islam mengajarkan kepada seseorang untuk senantiasa bertaqwa kepada Allah dengan cara mengamalkan sikap terpuji dalam kehidupan sehari-hari. Dengan mengamalkan sikap terpuji ini bukan saja berkaitan dengan hubungan seorang hamba dengan Allah, namun juga hubungan sesama manusia. Dalam konteks zakat, selain tujuannya untuk memenuhi tuntutan rukun Islam, namun berhubungan juga dengan pihak lua yaitu pembayar, asnaf dan amil serta pihakpihak yang ada dalam insitusi zakat itu sendiri. Hubungan ini diharapkan semua pihak agar senantiasa bersifat amanah, jujur, berintegritas dalam hal kepengurusan zakat. Namun, OPZ merupakan entitas yang memfasilitasi antara muzakki dan ashnaf. Namun demikian, OPZ bukanlah sebuah institusi yang bersifat steril dari perbuatan fraud (Naimi, et al, 2019). Oleh karena itu, perlu instrument pencegahan fraud diantaranya laporan keuangan yang akuntabel.

Menurut Albrecht et al. (2016) terdapat dua poin penting mekanisme pencegahan fraud yaitu mewujudkan budaya jujur, keterbukaan dan bantuan serta menghapuskan peluang melakukan fraud. Poin pertama dapat dilakukan dengan berusaha selalu bersikap jujur dan melatih sejak dini kesadaran fraud dan mewujudkan lingkungan kerja yang positif. Poin kedua dapat diwujudkan dengan menghapuskan peluang melakukan fraud, yaitu dengan cara, memiliki sistem pengendalian internal yang baik diantaranya melalui akuntabilitas laporan keuangan.

Fraud dalam laporan keuangan OPZ dapat diidentifikasi dari kebijakan akuntansi alokasi dan distribusi dana zakat dan infak/sedekah untuk mustahik yang meliputi dana amil dan non amil. Sebagaimana diketahui bahwa dana yang dihimpun dan disalurkan oleh BAZNAS merupakan amanah yang diberikan oleh muzaki dan orang-orang yang menitipkan dana sosial kepada BAZNAS, maka sangat diperlukan adanya transparansi dan pelaporan keuangan yang sesuai dengan SAK syariah, sehingga pelaporan keuangan dapat dipertanggungjawabkan baik secara individu maupun oleh perusahaan yang menitipkan dana sosial kepada BAZNAS.

Pelaporan keuangan, BAZNAS telah memiliki sistem pelaporan keuangan yang terkomputerisasi dan dapat diakses melalui website baznas.go.id. tetapi berdasarkan temuan penelitian Rahmi (2021) masih perbaikan sistem komputerisasi dan sistem pemantauan untuk mencegah terjadinya fraud dalam laporan keuangan yang disajikan. BAZNAS juga telah mewujudkan aspek 
Riskiyatur Rohemah ${ }^{1}$ dan Mohammad Nizarul Alim²: Laporan Keuangan Badan Amil Zakat Nasional (BAZNAS): Perspektif Akuntansi Syariah dan Pencegahan Fraud

transparansi dan kepercayaan publik dalam pengelolaan dana zakat, infak, dan sedekah melalui dokumentasi dan publikasi kegiatan dan laporan pertanggungjawaban yakni berupa laporan keuangan dengan memberikan informasi dan pengungkapan kepada publik pada laman website BAZNAS serta Laporan Keuangan Tahunan yang di publikasikan adalah laporan keuangan yang telah di audit oleh akuntan publik.

\section{KESIMPULAN}

Hasil penelitian ini memberikan kesimpulan bahwa laporan keuangan yang disajikan BAZNAS melalui proses terkomputerisasi dan komponen laporan keuangan BAZNAS memenuhi standar akuntansi syariah karena sesuai dengan PSAK 109 serta telah diaudit oleh akuntan publik independen. Tidak adanya akun dana non halal mengindikasikan BAZNAS hanya menggunakan rekening dari bank syariah dalam penerimaan dana zakat dan infak/sedekah maupun dana sosial lain. Transparansi dan akuntabilitas penerimaan dan penyaluran maupun pendayagunaan zakat telah disajikan dalam laman baznas.go.id sehingga publik dapat mengevaluasi dalam berbagai perspektif termasuk aspek syariah serta potensi fraudnya. Berdasarkan hasil penelitian, penelitian ini menyarankan agar tindak lanjut penelitian dengan melakukan observasi maupun diskusi dengan pihak yang memiliki otoritas di BAZNAS.

\section{DAFTAR PUSTAKA}

Albrecht, W.S., Albrecht, C.O., Albrecht, C.C. dan Zimbelman M. F. (2016). Fraud Examination,5th edition, Cengage Learning, Boston, USA.

A.Mubarok and W. Yadiati. (2017). Kualitas Pelaporan Keuangan. Jakarta: Kencana.

Ashiq, M., \& Mushtaq, U. "The Convergence of Crowd Funding and Zakat System in India: An Integrated Approach for Human Welfare". Ihtifaz: Journal of Islamic Economics, Finance, and Banking, 3(1) (2020), 27. https://doi.org/10.12928/ ijiefb.v3i1.1879

Azizah, S. N. (2018). Efektivitas Kinerja Keuangan Badan Amil Zakat Nasional (Baznas) pada Program Pentasharufan Dana Zakat di Baznas Kota Yogyakarta. El-Jizya: Jurnal Ekonomi Islam, 6(1), 91-112. https://doi.org/10.24090/ej.v6i1.2049

Badan Amil Zakat Nasional.(2016). https://pid.baznas.go.id/tahun-2016/

Badan Amil Sakat Nasional. (2019). https://pid.baznas.go.id/tahun-2019/

Charities Aid Foundation. (2021). World Giving. June, 1-42.

Effendi, M. A. (2016). The Power Of Good Corporate Governance: Teori Dan Implementasi. In Jakarta: Salemba Empat (Kedua). Salemba Empat.

Exposure Draft PSAK 109

Hartono, N., Prisila, H., \& Gustani. (2021). The Impact of Covid-19 on Zakat Shares Potential in Indonesia. International Journal of Zakat, 6(2), 15-26. 
Riskiyatur Rohemah ${ }^{1}$ dan Mohammad Nizarul Alim²: Laporan Keuangan Badan Amil Zakat Nasional (BAZNAS): Perspektif Akuntansi Syariah dan Pencegahan Fraud

https://ijazbaznas.com/index.php/journal/article/view/286

Hisamuddin, N., \& Sholikha, I. H. (2014). Persepsi, Penyajian dan Pengungkapan

Danan Non Halal pada Baznas dan PKPU Kabupaten Lumajang. Ziswaf, 1(1), 1-36.

Komite Nasional Keuangan Syariah. (2018). Masterplan Ekonomi Syariah Indonesia 2019-2024. Kementerian Perencanaan Pembangunan Nasional/ Badan

Perencanaan Pembangunan Nasional, 1-443.

https://knks.go.id/storage/upload/1573459280-Masterplan

Eksyar_Preview.pdf

Kustiawan, Teten. (2012). Pedoman Akuntansi Amil Zakat (Panduan Implementasi

Penyusunan Laporan Keuangan Berbasis PSAK 109. Jakarta : Forum Zakat

(FOZ).

Laporan Keuangan Tahunan BAZNAS Tahun 2016

Laporan Keuangan Tahunan BAZNAS Tahun 2017

Laporan Keuangan Tahunan BAZNAS Tahun 2018

Laporan Keuangan Tahunan BAZNAS Tahun 2019

Laporan Keuangan Tahunan BAZNAS Tahun 2020

Miah, M. A. (2021). Effectiveness of Zakat-based Poverty Alleviation Program: Evidence from Bangladesh. International Journal of Zakat, 6(2), 2021-2048.

Naimi, M., Nor, M., \& Abdul, D. (2019). Fraud Dan Mekanisme Pencegahan Di Institusi Zakat ( Fraud and Prevention Mechanism at Zakat Institution ). Proceedings of the 1st Kedah International Zakat Conference 2019 (KEIZAC 2019) Pp. 233-243, 2019(Keizac), 233-243.

Nugraha, S., Wardayati, S., \& Sayekti, Y. (2018). Implementation of Zakat Accounting In Amil Zakat Institute (LAZ) In Jember (Reviewed From Zakah Shariah : PSAK 101 And PSAK 109). International Journal of New Technology and Research, 4(1), 263155.

Nurhayati, Mardini, R., Rusman, Ku, K. M., \& Rusly, F. H. (2021). The Influence Internal Control System on the Quality of Financial Statements of BAZNAS of Indonesia. Proceedings of the Social and Humanities Research Symposium (SORES 2020), 562(Sores 2020), 117-121. https:// doi.org/10.2991/assehr.k.210617.024

Pamuncak, M. B., Possumah, B. T., \& Karimah, D. A. (2021). Investigating Zakat Institution Performance in Indonesia : a DnD analysis on PSAK Shariah No . 109. International Journal of Zakat (IJAZ), 6(2), 91-104. https://ijazbaznas.com/index.php/journal/article/view/282/110

Pratama, A. P., Disemadi, H. S., \& Paramita Prananingtyas. (2020). Existence And Position Of Islamic Laws In Indoneisa. Legality, 27(2), 222-231.

Rahman, T. (2015). AKUNTANSI ZAKAT, INFAK DAN SEDEKAH (PSAK 109): Upaya Peningkatan Transparansi dan Akuntabilitas Organisasi Pengelola Zakat (OPZ). Muqtasid: Jurnal Ekonomi Dan Perbankan Syariah, 6(1), 141.

https://doi.org/10.18326/muqtasid.v6i1.141-164

Rahmi, A. N. (2021). Sharia Accounting Literation and Frauds Preventive on 
Riskiyatur Rohemah ${ }^{1}$ dan Mohammad Nizarul Alim²: Laporan Keuangan Badan Amil Zakat Nasional (BAZNAS): Perspektif Akuntansi Syariah dan Pencegahan Fraud

Financial Reporting in Sharia Financial Institutions. ISLAMICONOMIC: Jurnal Ekonomi Islam, 12(1), 73-92. https:/ / doi.org/10.32678/ijei.v12i1.283

Saidah, R. (2020). Analisis Penyusunan Laporan Keuangan Badan Amil Zakat Nasional (BAZNAS) Kabupaten Kuantan Singingi Berdasarkan Pernyataan Standar Akuntansi Keuangan (PSAK NO 109). Juhanperak, 1(2), 571-583.

Wahab, N., Zainol, Z., \& Abu Bakar, M. (2017). Towards developing service quality index for zakat institutions. Journal of Islamic Accounting and Business Research, 8(3), 326-333. https://doi.org/10.1108/JIABR-09-2015-0040 